\title{
WEAK CONVERGENCE OF BOUNDED SEQUENCES
}

\author{
JOHN RAINWATER
}

The purpose of this note is to give a criterion for the weak convergence of a bounded sequence in a Banach space. The author wishes to acknowledge extremely useful conversations with E. Bishop, W. Eberlein, K. de Leeuw, V. Pták and W. Rudin.

If $B$ is a Banach space, let $U^{*}=\left\{f: f \in B^{*}\right.$ and $\left.\|f\| \leqq 1\right\}$ be the unit ball of $B^{*}$ and let $E$ be the set of extreme points of $U^{*}$.

THEOREM. Suppose that $\left\{x_{n}\right\}$ is a bounded sequence in the Banach space $B$, and let $x \in B$. Then $\left\{x_{n}\right\}$ converges weakly to $x$ if (and only if) $\lim _{n \rightarrow \infty} f\left(x_{n}\right)=f(x)$ for each $f$ in $E$.

Proof. Assume that $\left\|x_{n}\right\| \leqq M, n=1,2, \cdots$. It suffices to show that for each $g$ in $U^{*}, \lim g\left(x_{n}\right)=g(x)$. Now, $U^{*}$ is convex and compact (we only consider $U^{*}$ in its weak* topology) and the function $Q$ defined by $(Q x)(h)=h(x)$ for $x$ in $B, h$ in $U^{*}$, is a linear isometry of $B$ into $C\left(U^{*}\right)$, the space of continuous functions on $U^{*}$ with the supremum norm. Suppose that $g$ is an element of $U^{*}$. By the Bishopde Leeuw generalization [1, Theorem 5.6] of a well-known result of Choquet, there exists a $\sigma$-ring of subsets of $U^{*}$ (generated by $E$ and the Baire sets) and a non-negative finite measure $\mu$ on this $\sigma$-ring such that $\mu\left(U^{*}\right)=\mu(E)$ and $g(y)=\int_{U^{*}} Q y d \mu$ for each $y$ in $B$. Since $\mu\left(U^{*} \sim E\right)=0$, it follows that the functions $Q x_{n}$ converge to $Q x$ almost everywhere with respect to $\mu$. Since $\left|Q x_{n}\right| \leqq\left\|Q x_{n}\right\|=\left\|x_{n}\right\| \leqq M$, we conclude from Lebesgue's bounded convergence theorem that $g(x)=\int Q x d \mu=\lim \int Q x_{n} d \mu=\lim g\left(x_{n}\right)$, which completes the proof.

\section{BIBLIOGRAPHY}

1. E. Bishop and $\mathrm{K}$. de Leeuw, The representation of linear functionals by measures on sets of extreme points, Ann. Inst. Fourier (Grenoble) 9 (1959), 305-331.

UNIVERSITY OF WASHINGTON

Received by the editors March 18, 1963. 